\title{
WORKSHOP REPORTS from the Conference on the INFORMATION NEEDS OF THE EARTHQUAKE INSURANCE INDUSTRY IN NEW ZEALAND
}

\section{INTRODUCTION}

This conference was held in christchurch on 27-28 November 1989. It was followed the next day by the meeting of four workshop groups in the morning and a reporting back to a plenary session in the afternoon. These reports are currently being studied by a committee set up for this purpose by the Insurance council of New Zealand and which includes people from a range of relevant disciples. This committee has yet to report.

WORKSHOP - "TECHNICAL REGULATORY CONSIDERATIONS RELATED TO EARTHOUARE RISK"

\section{INTRODUCTION}

The workshop group was made up of a mix of engineering and insurance representatives.

Given the definition of 'Regulation' as being applied to technical building standards, e.g. the place of regulation versus the freedom of choice, owners' responsibilities, and the potential range of engineering solutions, it was realised that it was not practical to recommend specific details for such regulation.

There was varied and interesting discussion on topics of common interest, with a continuing exchange of ideas and concerns.

\section{COMMENT ON THE CONFERENCE}

The workshop participants reported a feeling of increased awareness of the phenomenon of earthquakes and their effects among insurance people. There also appeared to be a desire for insurance industry $\mathrm{co}-$ operation, noting that such co-operation is subject to commercial pressure, with a responsibility to service the public and meet shareholders' expectations.

Competition amongst insurance companies could distort the information needs across these companies.

The future approach, based on information as presented at the conference, depends on the insurance industry approach to a differential rating system.

The final requirements of Government Legislation now under consideration including elements of compulsion, and changing consumer and public pressure, may lead to a rating control of insurance premium price, in turn leading to a need for accurate information. There could be a rapid change in information needs with the passing of this legislation.

In any case, the collection and presentation of information should initially be directed at identification of the factors that need to be considered by the earthquake insurance industry in New Zealand.

\section{EARTHOUAKE HAZARD}

New Zealand Standards set levels for the earthquake resistant design (of buildings), in particular by setting the hazard level of the design earthquake. The current revision $s$ of the loading code proposes using New Zealand earthquake zones closely based on uniform risk spectra. This will tend to equalise the probability of severe structural damage occurring in the building throughout all areas of the country. This concept is in line with the proposed new building regulations with a focus on a consistency of risk for the safety of people.

The variation in building standards over the years means that the earthquake resistant performance will in turn vary with the year built. Adoption of a new loading code will add another step in this mix of building stock to the considered in assessments for insurance proposes.

Considering new buildings stock for insurance purposes, the uniform risk approach reduces the need to differentiate New Zealand earthquake zones for building damage. But it should be noted that there will still be a variability in frequency of claims for other property damage etc. from areas with more frequent smaller earthquakes.

There will be a need for public education on the concept of uniform risk for building standards, e.g. the public perception of the uniform risk approach when comparing the apparent relative seismicity of Auckland and Wellington.

\section{MICROZONING}

Microzoning of metropolitan areas is a key issue in determination of the hazard in similar terms and being equally as valid as 
the use of national earthquake zones.

Insurance risk studies appropriately do take microzoning into consideration.

Since microzoning is an element of insurance exposure, studies are strongly supported as a priority. Such studies should be carried out on a co-operation basis to maximise common benefits, it being noted that while insurance companies are competing, there are other areas in which to broaden their rating base.

It was noted that:

- The Earthquake and War Damage Commission Earthquake Research Foundation is founding microzoning studies, as well as studies being undertaken by Regional Councils.

- Such studies may become a requirement under conditions of the Resource Management Law Reform.

In consideration of Planning Regulations to perhaps restrict types and purposes of construction in areas of amplified earthquake effects, it was resolved that regulation should not restrict freedom of choice in concerns other than for health and safety. At the same time the Upper Hutt city council action in restricting on buildings within $20 \mathrm{~m}$ of the Wellington Fault, was recognised as an appropriate measure.

The insurance industry cannot establish internal regulations to penalise construction in more hazardous areas, due to conflict with the commerce Act.

\section{VULNERABILITY}

The insurance industry needs more information on the earthquake vulnerability of their property portfolios. Such vulnerability includes shake damage to the building as a whole, to the structure, secondary elements, architectural elements and contents, as well as other earthquake effects including fire, ground effects and damage from adjacent buildings, plus the potential for loss of function and business interruption claims.

Earthquake engineers need guidance on the type and nature of information on building vulnerability that would better suit the insurance industry.

Active co-operation of owners, insurance industry, local authorities and the engineering profession is needed to provide vulnerability information. Eventually there is potential for a common shared database of building information. From common information it would be up to the insurance company to use it sensibly and logically, matching exposure to portfolios. Legislation similar to that for personal information may be required for building information.

Further study to review building performance data from previous earthquakes, e.g. Gisborne and Inangahua, or to actively secure data from overseas earthquakes, e.g. Whittier, San Francisco, is commended.

\section{REGULATION OF THE EARTHOUAKE INSURANCE INDUSTRY}

Following the interest of those members of the insurance industry present at the workshop, attention was directed to consideration of regulation of the insurance industry.

It was generally recognised that legislation may be necessary to ensure that in a major catastrophe, the claims are met. There was general concern for the needs of prudential regulations to protect against insolvency, even to the extent of reviewing the reinsurance held.

Means must be found to prevent insurance companies being established that can gamble on the long term event not occurring.

The problem of realisation of the assets into cash for payment of claims following a major earthquake was recognised.

It was noted that cyclone Hugo is the biggest international reinsurance claim to date, and that the market has never been tested for the three times grater claim potential possible from New Zealand.

In conclusion it was noted that for prudential control, the cost of a potential catastrophe has to be assessed, requiring all of that information that has been discussed at this conference.

WORKSHOP - "THE COLLECTION AND APPLICATION OF INSURANCE RISR DATA"

Role - To draw on the relevant material and issues presented during the conference, to debate and reach a consensus view on those issues and to establish a means whereby dialogue and exchange of information can continue between the interested parties.

objectives - (a) to identify areas of common understanding and

(b) to identify areas requiring further study and research.

There was a very interesting discussion of a good cross section of the industry: consumers, reinsurers, reinsurance brokers, insurance brokers, actuaries, and earthquake engineers.

Some very real concerns were expressed particularly with the state of the market. The likelihood of irresponsible competition which could undermine any concerned efforts 
to improve the underwritng of catastrophe risk.

Briefly the wider range of the discussion covered the following points:

1. A well established earthquake rating scale would assist reinsurance brokers in placing catastrophe programmes.

2. The public need to be educated on the problems of underwriting disaster insurance. They are used to a uniform low level of cost.

3. There were concerns with suggestions of a sophisticated differential rating scale system.

4. There was a view that E.Q.C. should be seen to be setting minimum guidelines for domestic risks.

5. There were concerns there would be an increase in first loss covers, and a move towards writing smaller lines, and buying layers rather than the historical method of full value policies.

6. Insurers should consider a core working for disaster non act cover.

There was a consensus view that a working party should be set up by the industry with no more than five representatives but who would involve other interested disciplines as the need arose. The working party should be initiated and led by the Insurance Council of New Zealand and the core members should be -

\section{Insurers and $\mathrm{EQC}$}

Reinsurers and reinsurance brokers

Earthquake Engineers

Brett Fawcett for B.I.

The other disciplines to be called in as the need arises are:

\section{Volcanologists}

Engineers

Actuaries

Local Government

Valuing Groups

Institute of Loss Adjusters (Material Damage)

This working party should produce some guidelines such as:

1. Standard methodology for maximum probable loss assessment (noting that B.I. is most important) and we are aware several companies have already done some considerable work in both material damage and Business Interruption. There clearly seemed to be a willingness to share this information.

The guidelines could provide an advisory domestic and commercial rating structure primarily for earthquake. This would identify hazard zones and relate these to Cresta Zones.

The tariff structure is to be kept simple with say four (4) hazard zones and incorporate building classification which would be, type of construction, for example dwelling - wood and brick. Commercial would be - steel, reinforced concrete, masonry.

The third factor in the tariff would be subsoil.

It was suggested a range of standard deductibles be geared to the rates per hazard zone but to be aware of the problems caused if they get to a too high a level, e.g. San Francisco.

More work should be done in the taxation area on catastrophe reserve by lobbying government.

There were real offers of assistance from our overseas friends who participated and these have been duly noted with gratitude and will be passed on to the working party when it gets underway.

\section{WORKSHOP - "NATIONAL COST IYPLICATIONS OF EARTHOUAKE DISASTER}

In the light of the developing evidence of the inevitability of a major seismic event involving a heavily populated area, this conference is concerned that the potential of the economic and social disaster for New Zealand is not being addressed by central Government.

Whilst the insurance industry recognises its key role in any recover situation and accepts such responsibilities, the need for a detailed disaster plan on a national basis is seen as imperative to the country's survival.

This Conference therefore stresses the immediate need to establish a working party with Government to structure and implement a detailed plan to which purpose conference has prepared an outline of the major and significant areas requiring attention.

\section{IT WAS RESOLVED}

that the 1989 Conference "INFORMATION NEEDS OF THE EARTHQUAKE INSURANCE INDUSTRY IN NEW ZEALAND" notes the recommendations of its four conference working parties appended to this resolution.

It requests EQC to convene as soon as possible a further meeting of the conference steering committee who shall have the tasks of :

1. organising a permanent working party to advise how the recommendations of the four conference working parties might be promoted and implemented and

2. Approaching government and other relevant or interested bodies or persons to promote implementation of the recommendations. 


\section{WORKSHOP - "THE ROLE OF NATURAL SCIENCE IN IDENTIYING RISR"}

Our topic was subject to redefinition because of difficulty with the work "risk". It was redefined as -

"The role of science and engineering in identifying the hazard, vulnerability and the risk".

We conjecture as to who are the gamblers.

The scientists who provide the figures or the insurers who rely on them. One of the most important matters to come out our workshop was that the information needs of the insurance industry need to be crystallised for the scientific and engineering disciplines to provide an effective role.

Some insurance needs have of course already been crystallised - such as the constant call to know of the possible maximum loss.

The role of science is of course particularly relevant to material damage it has a limited part to play in other forms of insurance loss. A number of recommendations came from the workshop.

They are summarised as follows:

1. That there be encouragement for broad based funding of research and wide sharing of resultant knowledge;

2. That some priority be developed between the scientific and engineering community and the insurance industry for the ordering and development of that research;
3. That the scientific and engineering community work to make presently available information accessible and useful;

4. That urgent consideration be given to means of dealing with the social consequences of earthquake forecasting. There was a view that the use of the work "forecasting" be favoured as opposed to the word "prediction".

5. That we work to improve the reliability of hazard estimation. The science and engineering disciplines have an important role to play in the microzoning of New Zealand to determine variability of ground conditions and its relationship to damage ratios. The need for this work to be carried out has been evidenced in New Zealand Gisborne 1967 and of course recently in San Francisco. Microzoning is here defined as the variability of ground response to earthquake shaking dependent upon materials, earthquake sources and topography.

6. There was a strong final recommendation that there be continuing discussion and dialogue between the disciplines not just to determine the prioritising and development of research but also the harmonising of record collection within the insurance industry to facilitate the role of science and engineering in identifying the hazard, vulnerability and the risk. 